\title{
ESPAÇO DE ENCONTROS: \\ CRENÇAS E ATITUDES \\ LINGUÍSTICAS NAS FRONTEIRAS \\ BRASIL/ARGENTINA E BRASIL/ \\ PARAGUAI
}

Angélica Margaret Barbosa Cortez ${ }^{1}$

Sanimar Busse ${ }^{2}$

\begin{abstract}
Resumo: Neste artigo pretendemos discutir a teoria e a metodologia da pesquisa que está sendo desenvolvida no Programa de Pós-Graduação - Mestrado em Letras, sobre crenças e atitudes linguísticas. O objetivo principal da pesquisa é analisar as crenças e atitudes linguísticas de moradores das fronteiras Brasil/Argentina sobre o espanhol, a partir dos dados coletados em Santo Antônio do Sudoeste-BR, Capanema-BR, e das fronteiras Brasil/Paraguai, nos municípios de Guaíra-BR e Foz do Iguaçu-BR. As entrevistas que compõem o corpus da pesquisa foram realizadas no Projeto crenças e atitudes linguísticas: um estudo da relação do português com línguas de contato (SELLA; AGUILERA, 2009). Para nortear o estudo, utilizamos o escopo teórico da Sociolinguística (LABOV, 1976), das Crenças e Atitudes Linguísticas (LAMBERT, 1967; AGUILERA, 2008).
\end{abstract}

Palavras-chave: Crenças e atitudes linguísticas; Fronteira; Línguas em contato.

\section{MEETING SPACE: LINGUISTIC BELIEFS AND ATTITUDES IN BRAZIL/ARGENTINA AND BRAZIL/PARAGUAY BORDERS}

\begin{abstract}
In this article we intend to discuss the theory and methodology of the research that is being developed in the Graduate Program - Master's degree in Letters, about linguistic beliefs and attitudes. The main objective of the research is to analyze the beliefs and linguistic attitudes of residents in Brazil / Argentina borders on Spanish, from the data collected in the counties of Santo Antônio do SudoesteBR, Capanema-BR, and the Brazil / Paraguay borders, in the municipalities of Guaira-BR and Foz do Iguaçu-BR. The interviews which makes the corpus of the research, were conducted in the Project Beliefs and Linguistic Attitudes: A Study of the Relationship of the Portuguese language with Contact Languages (SELLA; AGUILERA, 2009). To guide the study, we used the theoretical scope of Sociolinguistics (LABOV, 1976), Beliefs and Linguistic Attitudes (LAMBERT, 1967; AGUILERA, 2008).
\end{abstract}

Keywords: Linguistic beliefs and attitudes; Border; Languages in contact.

1 Mestranda em Letras. Universidade Estadual do Oeste do Paraná (UNIOESTE) Cascavel-PR. angelicambcortez@gmail. com. http:/ /lattes.cnpq.br/4203066501759444

2 Doutora em Letras. Universidade Estadual do Oeste do Paraná (UNIOESTE) Cascavel-PR. sani_mar@yahoo.com.br. http:/ /lattes.cnpq.br/ 6743779015422687 


\section{INTRODUÇÃO}

O Brasil, por sua vasta extensão territorial, faz fronteira com vários países hispânicos. As regiões fronteiriças são marcadas por complexidades identitárias, linguísticas e culturais, o que faz com que sejam singulares e múltiplas.

Pelo viés da vertente sociolinguística, neste artigo pretendemos discutir, preliminarmente, a teoria e a metodologia utilizada para uma pesquisa de dissertação de Mestrado sobre crenças e atitudes linguísticas. Como a pesquisa ainda está em andamento, não serão apresentados resultados.

O contexto abordado para a pesquisa são as regiões brasileiras paranaenses, que fazem fronteira com a Argentina e o Paraguai. Esses municípios estão inseridos em uma zona fronteiriça e, por isso, são marcados, entre outros fatores, pela coexistência de diferentes línguas. Para a pesquisa, tomaremos o português e o espanhol, que são as línguas oficiais dos referidos países.

Nesse sentido, o objetivo da pesquisa é analisar as crenças e atitudes linguísticas de moradores das fronteiras Brasil/Argentina dos municípios de Santo Antônio do Sudoeste-BR, Capanema-BR e das fronteiras Brasil/Paraguai, municípios de Guaíra-BR e Foz do Iguaçu-BR, sobre a língua espanhola.

Além da complexidade linguística, os aspectos culturais também se mesclam, e com esse movimento vêm os valores, os (pré)conceitos, assim como as crenças e atitudes em relação ao outro. Estudar as crenças e atitudes linguísticas nessas regiões fronteiriças específicas é ter a oportunidade de compreender como se dão as mudanças, identificar o posicionamento de um sujeito em relação à língua do outro e entender como isso pode influenciar de tal modo a gerar consequências ao longo do tempo.

A partir dessa análise poderemos compreender, dentro das relações estabelecidas nessas comunidades, quais componentes cognoscitivo (saber ou crença), afetivo (sentimento/ valoração) ou conativo (conduta sociolinguística) - (LAMBERT; LAMBERT, 1975) atuam sobre as crenças e atitudes linguísticas de falantes do português sobre o espanhol nas localidades investigadas para a constituição histórica das localidades e das variáveis sociais (sexo, faixa etária, classe social e nível de escolaridade).

Diante da complexa relação que se estabelece na fronteira, principalmente, no que se refere à língua, a pesquisa busca responder as seguintes perguntas: (i) Quais fatores implicam nas crenças e atitudes linguísticas dos falantes de português sobre o espanhol? (ii) Quais são as crenças e atitudes linguísticas dos falantes de português sobre o espanhol? (iii) Quais fatores atuam para a formação das identidades linguísticas dos moradores de Santo Antônio do Sudoeste-BR, Capanema-BR, GuaíraBR e Foz do Iguaçu-BR?

Este artigo está em dividido em quatro seções, na primeira refletimos brevemente acerca da sociolinguística, línguas em contato e crenças e atitudes linguísticas; na segunda, abordamos aspectos de línguas de fronteira; a terceira é sobre identidades linguísticas, seguida da metodologia e das considerações finais.

\section{REFLEXÃO SOBRE VARIAÇÃO E DIVERSIDADE LINGUÍSTICA (SOCIOLINGUÍSTICA, LÍNGUASEM CONTATO, CRENÇAS E ATITUDES LINGUÍSTICAS)}

\section{A Sociolinguística}

A Sociolinguística aborda diversos estudos, como o contato entre as línguas, o multilinguismo, surgimento ou extinção linguística, variação e mudança na língua. (MOLLICA, 2019).

Dentre esses estudos, a Sociolinguística considera, em especial, o estudo da variação, 
como objeto de estudo, "entendendo-a como um princípio geral e universal, passível de ser descrita e analisada cientificamente. Ela parte do pressuposto de que as alternâncias de uso são influenciadas por fatores estruturais e sociais." (MOLLICA, 2019, p. 09-10).

Assim, a variação pode ocorrer em dois eixos: diatópico e diastrático. Segundo Mollica (2019): "No primeiro, as alternâncias se expressam regionalmente, considerando-se os limites físicogeográficos; no segundo, elas se manifestam de acordo com os diferentes estratos sociais, levandose em conta as fronteiras sociais." (MOLLICA, 2019, p. 12). Nesse sentido, as variações, presentes nas comunidades, seja no eixo diatópico diastrático, ou de outra ordem, levam a uma diversidade linguística, que move os estudos sociolinguísticos.

Busse (2010) evidencia que o falante usa das formas da tradição linguística de sua comunidade, masisso não impede que ele acolha outros elementos, "obedecendo às condições externas e internas da língua." Nesse sentido, segundo a autora, não é a língua que se impõe ao falante, como estrutura, mas ela "[...] se oferece como possibilidade de uso diante do conjunto de dimensões que orientam aquela situação comunicativa." (BUSSE, 2010, p. 42).

Desse modo, nosso olhar se volta para o contato linguístico que há nas regiões fronteiriças do sudoeste e oeste paranaense e, especificamente, para as crenças e atitudes linguísticas que se manifestam na fala desses sujeitos que vivem na fronteira, lugar em que as línguas são postas em situação de "convivência" e de "confronto", como diz Alvarez (2011, p. 01).

A autora ainda afirma que o sujeito se representa como político ao dizer "as/nas línguas de fronteira", o que significa "[...] estar dividido entre as línguas, já que em sua língua de enunciar, evidencia materialmente um espaço de enunciação fronteiriço, cujas línguas afetam de maneira singular os falantes." (ALVAREZ, 2011, p. 01). O posicionamento político está pautado pelas representações do sujeito, pelas crenças e atitudes que o constituíram ao longo da vida e que o fazem ter reações positivas ou negativas em relação a algo ou a alguém.

\subsection{Línguas em Contato}

O resultado dos contatos linguísticos também são uns dos principais estudos da Sociolinguística (CALVET, 2002), que é parte de sociedades em que duas ou mais línguas se envolvem, produzindo “interferências, alternâncias e estratégias" (CALVET, 2002, p. 42).

Esses contatos se dão em diversas regiões do Brasil, especialmente pela miscigenação, nas palavras de Brandão (1991) “decorrente do processo de povoamento e colonização a que foi submetido" (BRANDÃO, 1991, p. 16), e pela diversidade cultural e linguística que há em nosso país.

Nas regiões fronteiriças abordadas para a pesquisa, é comum os cidadãos atravessarem as aduanas para as mais diversas atividades, como passear, comprar, trabalhar, visitar a família e/ ou amigos. A partir dessa convivência e do ato de comunicar-se seja em português, espanhol ou portunhol3, as línguas entram em contato.

Assim, as línguas em contato se dão em contextos de comunidades em que as relações entre os povos se estreitam e que há uma diversidade linguística. Calvet (2002) explica que "O plurilinguismo faz com que as línguas estejam constantemente em contato" e que o lugar desses contatos pode ser o indivíduo, seja ele bilíngue ou em aquisição ou mesmo, a comunidade. (CALVET, 2002, p. 27).

3 De acordo com Sturza (2006): 'O "Portunhol" designa uma prática lingüística deficitária, uma passagem entre uma língua e outra, por isso nem uma língua nem outra.' (STURZA, 2006, p. 131). 
Nesse sentido, para Fabrício (2006), há um "vínculo indissociável entre linguagem, produção de sentidos, contexto, comportamento social e atividades humanas, o que aponta para o entrelaçamento entre cultura, práticas discursivas, conhecimento e visão de mundo.” (FABRÍCIO, 2006, p. 57). Viver (na) a fronteira é entrelaçarse com o outro, com a cultura do outro, além de estar sempre em constante transformação, pois é um processo que não se acaba. Nesse processo, por meio da interação e das vivências, se dão os posicionamentos e a partir disso, as opiniões, as crenças e as atitudes linguísticas.

\subsection{Crenças linguísticas e atitudes linguísticas}

A língua que falamos nos representa como sujeitos, é a nossa identidade. Assim, há uma complexa relação entre língua, sociedade e identidade, inerente aos falantes e que provoca neles posicionamentos frente à língua ou à variedade linguística, assim como aos usuários delas (AGUILERA, 2008).

De acordo com Labov (2008) “[...] uma comunidade de fala não pode ser concebida como um grupo de falantes que usam todos as mesmas formas; ela é mais bem definida como um grupo que compartilha as mesmas normas a respeito da língua" (LABOV, 2008, p. 188). Portanto, as ações de compartilhar as mesmas normas são decorrentes das emoções, intenções, percepções e opiniões construídas a partir da vivência de cada pessoa, provenientes das relações cotidianas e do que se aprende no senso comum, que desencadeiam em crenças - pensamentos, racionalidade, sentimentos, que nas exposições do sujeito, resultam em (re) ações, em atitudes, que podem ser positivas, neutras ou negativas.

Silva e Aguilera (2014) salientam que as atitudes desencadeadas pelos indivíduos são movidas pelas crenças linguísticas fixadas pela sociedade na língua e nos dialetos, o que leva a manifestações que desencadeiam em "atitudes de rejeição ou de aceitação, de preconceito ou prestígio, de correção ou de erro, dentre outras. (SILVA; AGUILERA, 2014, p. 705).

Assim, destacamos os estudos da psicologia social, que refletem a respeito das condições cotidianas de julgamentos e acontecimentos sociais (LAMBERT; LAMBERT, 1975), além de estarem "interessados por estados de emoções em outros, intenções das pessoas, bem como pelas percepções que os indivíduos têm de ordens sociais hierárquicas em seus grupos." (LAMBERT; LAMBERT, 1975, p. 63). Segundo Calvet (2002):

[...] existe todo um conjunto de atitudes, de sentimentos dos falantes para com suas línguas, para com as variedades de línguas e para com aqueles que as utilizam, que torna superficial a análise da língua como simples instrumento. Pode-se amar ou não um martelo, sem que isso mude em nada o modo de pregar um prego, enquanto as atitudes linguísticas exercem influências sobre o comportamento linguístico. (CALVET, 2002, p. 57).

Lambert e Lambert (1975), definem que: "Nossas atitudes se desenvolvem quando enfrentamos nossos ambientes sociais e nos ajustamos a eles. Uma vez criadas as atitudes, estas levam regularmente a nossos modos de reagir e facilitam o ajustamento social." (LAMBERT; LAMBERT, 1975, p. 101). Então, a interação social, os diálogos, e as relações entre os sujeitos, são elementos fundamentais que determinam certas atitudes, e, de acordo com Moreno Fernández (2009), as atitudes implicam em componentes de caráter afetivo, crenças e condutas.

\section{LÍNGUAS DE FRONTEIRA}

A demarcação das fronteiras nas regiões destacadas para este estudo, em geral, se dá por travessias como pontes. Essa travessia é feita 
muitas vezes, por várias pessoas ao longo do dia, até mesmo para trabalhar no país vizinho.

Sendo assim, argentinos, paraguaios e brasileiros estreitam suas relações com as pessoas que habitam o outro país. Do estreitamento ocorrem casamentos, amizades, passeios, trabalhos, compras, apesar da aduana, já que a cada travessia devem ser mostrados documentos e explicados os motivos pelos quais a pessoa está se deslocando até o outro país.

A fim de analisarmos as crenças e atitudes linguísticas de sujeitos fronteiriços, é necessário que compreendamos o que ponderam alguns autores acerca desse espaço. Segundo Sturza (2006):

Fronteira se define por uma relação com o real, simbolizada através de uma referência física que indica sua existência, como os marcos que representam os limites territoriais. Por outro lado, apresenta outro sentido de integração, de interface, que é fluido, tal como se dá a mistura das línguas. (STURZA, 2006, p. 31)

Essa reflexão da autora nos leva a pensar no viver fronteiriço como em duas vertentes, uma como uma referência física, em que há o marco, as pontes, as placas, as delimitações, e outra em que as pessoas conversam em um contato real, sem pensar nos limites, nas diferenças, quando a integração simplesmente acontece. Isso porque, de acordo com Maia (2002):

\footnotetext{
Nestes casos, em que podem existir acidentes geográficos, políticos e normas marcando uma divisão, também pode constituir-se uma mesma comunidade e pode-se dizer: "eu sou da Argentina" ou "eu sou do Brasil", mas isto não impede que do outro lado esteja morando meu irmão, o meu primo, ou, quem sabe, até mesmo os meus filhos, e não se pode delimitar a cultura desta comunidade e seus diferentes idiomas que seguem vivos e circulando de um país a outro sem fronteira. (MAIA, 2002, p. 96).
}

Uns moram no Brasil, outros na Argentina ou no Paraguai, mas pela proximidade, o encontro e o diálogo entre essas pessoas são possíveis, assim como as identificações e, claro, as complexidades que podem surgir dessas relações. Nesse sentido, para Alvarez (2009), a fronteira:

[...] não representa apenas uma 'línea de defesa' ou um trânsito de lugar, mas sim lugar de condições propícias para o diálogo, para o intercâmbio, para o ir e vir. As fronteiras são definidas pelo que podem configurar enquanto um espaço novo que se caracteriza pela mobilidade e dinamismo das comunidades pertencentes. (ALVAREZ, 2009, p. 26, grifos da autora).

A partir do diálogo e desse intercâmbio dito pela autora, a fronteira se transforma, se (re) constrói por meio das vivências dos sujeitos que a habitam e escrevem e reescrevem a história a todo o momento.

Embora a fronteira seja lembrada e vista como espaço cultural, identitário, múltiplo que é, vale ressaltar que as histórias fronteiriças foram marcadas por batalhas e são o "[...] resultado de una historia más o menos larga, más o menos violenta" (ROA BASTOS, 2013, p. 25)4. Segundo o autor, "Las fronteras están, frecuentemente, guardadas militarmente contra el peligro exterior, contra los extranjeros, sospechosos de desear violar la frontera e invadir el territorio propio." (ROA BASTOS, 2013, p. 26)5.

Os espaços de fronteira, chamados por Roa Bastos de "zonas de contacto", são espaços diferentes, naturalmente, e isso se deve a múltiplos fatores, mas, de acordo com o autor, a intensidade de intercâmbios e as diferenças mais ou menos importantes de um lado ou de outro, dão a essas regiões, características específicas. Nessas relações surgem os encontros e desencontros proporcionados pelas diferenças culturais, identitárias e também linguísticas.

4 “[... resultado de uma história mais ou menos comprida, mais ou menos violenta." (ROA BASTOS, 2013, p. 25, tradução nossa).

5 "As fronteiras estão, frequentemente, guardadas militarmente contra o perigo exterior, contra os estrangeiros, suspeitos de desejar violar a fronteira e invadir o território." (ROA BASTOS, 2013, p. 26, tradução nossa). 


\section{IDENTIDADES LINGUÍSTICAS}

Sturza (2006) explica que limites cartográficos referenciam a fronteira por meio de marcos "embora a vida da fronteira, o habitar a fronteira signifique, para quem nela vive, muito mais, porque ela já se define em si mesma como um espaço de contato, um espaço em que se tocam culturas, etnias, línguas, nações." (STURZA, 2006, p. 26). Ou seja, a fronteira é muito mais que um limite, é esse espaço de confluências de costumes, de representações, de proximidades e antagonismos, de conflitos e inconstâncias, seja no aspecto linguístico-cultural, seja no aspecto identitário.

A língua como uma materialização das práticas de significação e das representações, é dinâmica e transitória quanto as prprias representações (BRAZ, 2010). Assim como os aspectos culturais e de representação, a língua é plural e se reconstrói a todo o tempo.

Alguns acontecimentos definem as relações fronteiriças como complexas, como em situações de comunicação em que um indivíduo fala em espanhol e o outro responde em português, ou mesmo, quando os sujeitos acabam usando outras práticas linguísticas para interagir, como o portunhol, por exemplo, - modo de comunicação que se deu a partir da convivência entre os povos (RAJAGOPALAN, 2003) e que é recorrentemente usado pelos sujeitos que vivem na fronteira e reconhecido com esse nome.

No entanto, o portunhol não é considerado pelos falantes uma língua de prestígio, ou a desejada, mas muitas vezes é a prática linguística que as pessoas adotam para serem compreendidas. Sturza e Fernandes (2009) esclarecem: "Uma língua que funciona em estado de interface com a outra, pertencente a um conjunto de representações histórico-sociais e interculturais que as identificam como tal." (STURZA; FERNANDES, 2009, p. 212).
A representação que construímos das pessoas, das ações, dos objetos, por exemplo, é feita a partir da posição a outras pessoas, ações, objetos. Assim, quando representamos algo como "bom", fazemos a partir de uma relação do que julgamos como "mau". Essas representações se dão por meio das crenças que temos. De acordo com Barcelos (2007), crenças são:

\begin{abstract}
[...] uma forma de pensamento, construções da realidade, maneiras de ver e perceber o mundo e seus fenômenos, co-construídas em nossas experiências resultantes de um processo interativo de interpretação e (re) significação. Como tal, crenças são sociais (mas também individuais), dinâmicas, contextuais e paradoxais. (BARCELOS, 2007, p. 113).
\end{abstract}

Para a autora, as crenças têm origem nas nossas experiências, na cultura e no folclore e também podem ser internamente inconsistentes e contraditórias. (BARCELOS, 2001).

Além disso, das crenças vem as reações e as atitudes em relação ao outro. Isso acontece tamanha a importância que as atitudes têm na determinação dos nossos comportamentos, tanto que influem nos juízos e percepções que temos acerca das outras pessoas, na rapidez com que aprendemos algo, nos grupos aos quais nos ligamos, as profissões que escolhemos e até a filosofia que aceitamos. (LAMBERT; LAMBERT, 1975).

Portanto, segundo os psicólogos, as atitudes que desenvolvemos ao longo da vida, contribuem para a estrutura das nossas personalidades. Esse processo se dá desde a infância, por meio da interação com nossos pais, mas as atitudes vão se modificando com o passar do tempo de acordo com as experiências que o sujeito tiver, sejam positivas ou negativas.

\section{METODOLOGIA}

A pesquisa toma como corpus os dados coletados a partir de um questionário aplicado por meio do Projeto Crenças e Atitudes Linguísticas: 
um estudo da relação do português com línguas em contato, coordenado pela Professora Doutora Vanderci de Andrade Aguilera.

Para a pesquisa foram utilizados dois métodos, o qualitativo e o quantitativo. Minayo (2002) diz que o conjunto de dados quantitativos e qualitativos " $[. .$.$] se complementam, pois a realidade$ abrangida por eles interage dinamicamente, excluindo qualquer dicotomia." (MINAYO, 2002, p. 22). Uma pesquisa de cunho qualitativo é complexa no momento da construção do trabalho, pois requer um distanciamento entre os pesquisadores e a investigação. A pesquisa de cunho quantitativo é realizada no intuito de que haja precisão dos dados coletados, considerando que as informações são numéricas e objetivas.

Com o intuito de responder aos objetivos do estudo, a pesquisa de campo é: “[...] desenvolvida por meio da observação direta das atividades do grupo estudado e de entrevistas com informantes para captar suas explicações e interpretações do que ocorre no grupo." (GIL, 2002, p. 53). Nesse sentido, foram aplicados questionários nas localidades fronteiriças definidas para a pesquisa, a fim de levantar dados acerca das crenças e atitudes linguísticas dos falantes de português sobre o espanhol.

Souza e Antunes (2017) afirmam que: "As visões de mundo, as crenças, as ideologias de uma sociedade são transmitidas de geração a geração pela língua, falada e/ou escrita, evidenciando que a língua representa as marcas sociais e culturais de um povo." (SOUZA; ANTUNES, 2017, p. 10). Dessa maneira, a pesquisa também é de natureza etnográfica, já que possibilita analisar essas marcas sociais e culturais, especificamente as crenças e atitudes linguísticas de moradores das fronteiras Brasil/Argentina e Brasil/Paraguai, sobre a língua espanhola.

Silva, Oliveira, Pereira e Lima explicam que: “[...] a etnografia, como também outras pesquisas qualitativas, buscam a inserção no contexto natural para acessar às experiências, aos comportamentos, às interações e aos documentos para assim compreender a dinâmica do grupo estudado." (SILVA, et al., s.d., p. 04). Assim, por meio da pesquisa etnográfica, com análise às respostas das entrevistas, podemos compreender a sociedade a partir do olhar dos sujeitos que nela estão inseridos. Para obtermos os dados da pesquisa, primeiramente foram selecionadas as questões a serem analisadas. Assim, posteriormente realizaremos a quantificação, interpretação e análise das respostas obtidas por meio dos questionários. As respostas quantificadas serão organizadas em quadros e os dados da análise serão apresentados em quadros, gráficos e excertos. Os gráficos renderão dados que apontarão as crenças e atitudes linguísticas dos falantes de português sobre o espanhol.

Os excertos, criados a partir de uma análise descritiva das respostas dos sujeitos, permitirão que visualizemos as repostas e verifiquemos como se deram as crenças e atitudes linguísticas dos sujeitos a partir das respostas dadas nas entrevistas.

\section{CONCLUSÃO}

Neste artigo foram abordados os pressupostos teóricos e metodológicos utilizados para a pesquisa sobre crenças e atitudes linguísticas de moradores das fronteiras Brasil/Argentina sobre o espanhol, a partir dos dados coletados em Santo Antônio do Sudoeste-BR, Capanema-BR, e das fronteiras Brasil/Paraguai, nos municípios de Guaíra-BR e Foz do Iguaçu-BR.

Nessas regiões é comum que cidadãos elejam ouvir a rádio com programações em língua portuguesa ou espanhola, comunicar-se em ambas as línguas, ir e vir de um lado a outro, atravessando a aduana. Argentinos, paraguaios e brasileiros compram, trabalham, usufruem de vários serviços 
e residem nesse espaço em comum, apesar das aduanas, presente nas quatro fronteiras abordadas nesta pesquisa.

Assim, ocorre um estreitamento nas relações dos sujeitos fronteiriços, que ao mesmo tempo divide esse lugar e o multiplica pelas diferentes línguas, culturas, identidades e histórias. Dessa multiplicação, os resultados são bastante complexos e singulares, pois estão diretamente ligados às relações construídas entre os sujeitos e às crenças e atitudes que ocupam esse espaço.

O conviver é como uma cadeia de compartilhamentos e de confrontos de identidades, de culturas, peculiares do sujeito fronteiriço. As crenças, que levam as pessoas a gostar ou não, a se identificar ou não com o país vizinho, com o modo como se comportam, como falam, com os costumes, com a cultura, são complexas e difíceis de mudar, consequentemente as atitudes também, pois elas se fixam com o passar do tempo e são agregadas pelo sujeito, a determinado grupo em que são acolhidas.

Dessa maneira, no decorrer da pesquisa, ao realizarmos a análise dos dados e obtivermos os resultados, será possível responder às perguntas que nortearam nosso estudo sobre crenças e atitudes linguísticas nas regiões referidas e poderemos compreender as mudanças e interferências que esses comportamentos podem causar ao longo do tempo.

\section{REFERÊNCIAS}

ALVAREZ. Isaphi Marlene Jardim. Falar apaisanado: uma forma de designar as línguas na fronteira. 2009. 81 f. Dissertação (Mestrado em Letras). Universidade Federal de Santa Maria, Santa Maria. 2009.

ALVAREZ, Isaphi Marlene Jardim. Falar apaisanado: uma forma de designar as línguas na fronteira. Letrônica v. 4, n. 2, p.104-120, nov., 2011.
AGUILERA, Vanderci de Andrade. Crenças e atitudes linguísticas: o que dizem os falantes das capitais brasileiras. In. Estudos Linguísticos, São Paulo, 37 (2): 105-112, maio-ago. 2008.

BARCELOS, Ana Maria Ferreira. Metodologia de Pesquisa das Crenças sobre Aprendizagem de Línguas: Estado da Arte. Rev. Brasileira de Lingüística Aplicada, v.1, n.1, 71-92, 2001.

BARCELOS, Ana Maria Ferreira. Reflexões acerca da mudança e crenças sobre ensino e aprendizagem de línguas. Rev. Brasileira de Lingüística Aplicada. Belo Horizonte, v.7, n. 2, p. 109-138, 2007.

BRANDÃO, Silvia Figueiredo. A geografia linguística no Brasil. São Paulo: Ática, 1991.

BRAZ, Evodia de Souza. Línguas e identidades em Contexto de Fronteira Brasil/Venezuela. 2010. 120 f. Dissertação (Mestrado em Linguística Aplicada). Universidade Estadual de Campinas, São Paulo. 2010.

BUSSE, Sanimar. Um Estudo Geossociolinguístico da Fala do Oeste do Paraná. Tese de Doutorado (Pós-Graduação em Estudos da Linguagem) - Universidade Estadual de Londrina/UEL, Londrina. 2010.

CALVET, Louis-Jean. Sociolinguística: uma introdução crítica. São Paulo: Parábola, 2002.

GIL, Antônio Carlos. Como elaborar projetos de pesquisa. - 4. ed. - São Paulo: Atlas, 2002.

LAMBERT, William W.; LAMBERT, Wallace E. Psicologia Social. Rio de Janeiro: ZAHAR, 1975.

LABOV, William. Padrões Sociolinguísticos. São Paulo: Parábola, 2008.

MAIA, Ivene. (2002). Intercâmbios lingüísticos de fronteira: incidência no falar dos alunos do curso de português da U.NA.M. Perspectiva, Erechim: v. 26, n. 6, p. 95-101, dez.

MINAYO, Maria Cecília de Souza (org.) Pesquisa Social: teoria e método e criatividade. 13. ed. Petrópolis: Vozes, 2002. 
MOLLICA, Maria Cecília; BRAGA, Maria Luiza (Org.). Introdução à Sociolinguística: o tratamento da variação. 4.ed. $5^{\text {a }}$ reimpressão. - São Paulo: Contexto, 2019.

MORENO FERNÁNDEZ, Francisco. Principios de Sociolingüística y sociologia del lenguaje. 4.ed. Barcelona: Ariel, 2009.

RAJAGOPALAN, Kanavillil. Por uma lingüística crítica: linguagem, identidade e questão ética. São Paulo: Parábola Editorial, 2003.

ROA BASTOS, Augusto; DINIZ, Alai Garcia (Org.). Arquivos de fronteira. Tubarão: Copiart, 2013.

SILVA, Helen Cristina da; AGUILERA, Vanderci de Andrade. O poder de uma diferença: um estudo sobre Crenças e atitudes linguísticas. Alfa, São Paulo, 58 (3): 703-723, 2014.

SILVA, Maria Oneide Lino da. et al. Etnografia e pesquisa qualitativa: apontamentos sobre um caminho metodológico de investigação. s.d. Disponível em: http://leg.ufpi.br/subsiteFiles/ ppged/arquivos / files/VI.encontro.2010/GT.1/ GT_01_15.pdf Acesso em: 10 jul. 2019.

SOUZA, Geralda Fátima de; ANTUNES, Paulo Roberto. Etnolinguística: uma breve incursão. Ágora - A revista científica da FaSaR - Ano I - no 01 - Julho - 2017.

STURZA, Eliana Rosa. Línguas de fronteiras e política de línguas: uma história das idéias lingüísticas. 2006. 158 f. Tese (Doutorado em Linguística). Universidade Estadual de Campinas, Campinas, 2006.

STURZA, Eliana Rosa; FERNANDES, Ivani Cristina Silva. A fronteira como novo lugar de representação do espanhol no Brasil. In: Revista Signo \& Seña, n 20, p. 209-227, 2009.

Submissão: maio de 2020.

Aceite: janeiro de 2021. 